\title{
Boundary element modelling of wave diffraction by interaction with wave-offshore structure and dredged region
}

\author{
S. D. Kim, Ph.D. \\ Chung-Ang University, South Korea \\ H. J. Lee, Ph.D. \\ Colorado State University, USA
}

\begin{abstract}
The purpose of this study is to estimate the wave height at the front face of breakwater (Refracted breakwater and Straight breakwater), when dredging like the submarine pit is performed in the distant offshore from outer breakwater. The wave field of the problem is considered to be two dimensional planes and the configuration of the pit region is designated by a single horizontal long-rectangular system. The numerical approach uses the Green function based on the boundary integral approach. The results of the present numerical works are illustrated by applying the normal and inclined incidence. It is shown that in the case of normal incidence, the ratio of wave height reduction at the front face of both types of breakwaters is approximately more than $20 \%$ due to the effect of the submarine pit on the sea bed. Furthermore, regardless of the type of breakwater and the difference in incident wave angles, the ratio of wave height was shown to be reduced.
\end{abstract}

Keywords: Submarine pit; Green function; boundary integral approach; breakwater

\section{INTRODUCTION}

Study of wave diffraction by submarine pits has important application to coastal engineering. The purpose of this study is to investigate the reduction effect of wave height by submarine pit using depth-discontinuity. The early studies on the interaction of incident waves with a dredged region has been investigated by Newman (1965), Hilay (1969), Lee and Ayer (1981), Miles (1982), Kirby and Dalrymple (1983), Ting and Raichlen (1986), and Kirby et al. (1987). In all of these studies, the pit region was assumed to be infinitely long and the problem was restricted to the horizontal and vertical coordinates.

Later, Williams (1990) and McDougal et al. (1996) presented the numerical model for involving two horizontal planes in the case of single or multiple pits. The 3D (three dimensional) model, which is based on the Airy wave theory, was then investigated by Williams and Vazquez (1991) to analyze wave diffraction through a single pit. Recently, modeling diffraction of random waves by submarine pits has been investigated by Kim (2007). However, the focus in all of these studies were restricted to interaction of only one or two aspects, which occurred over pit (or trench) with discontinuity water depth.

The present study is about the interaction of wave, which is propagated over pit with discontinuity water depth. This study investigates the affect of this wave on the font face of breakwater systems (refracted and straight breakwater) when a pit is dredged. The wave interaction is connected to three boundary problems: the interaction of discontinuity water depth boundary and pit boundary, discontinuity water depth boundary within pit and breakwater boundary, and pit boundary and breakwater boundary. The problem is considered in a two dimensional plane, and the configuration of the dredging region on sea bed is a single-long rectangular type. The numerical simulation is performed by using the solution of the boundary integral equation based on the Green function.

In order to verify the present numerical model, comparisons made with the results of absolute and approximation solution presented by Koji and Mutsuo (1976) for regular wave diffraction at the front face of refracted breakwater without pit. Upon comparison, the present numerical simulation and the research by Koji and Mutsuo (1976) fell into relative agreement.

Decreasing effects of diffracted wave field in vicinity of breakwater due to a pit with discontinuity water depth were shown. The present study can provide information to design the dredge line of the outer breakwater that is distant from this dredge line. This study can also be effectively utilized for wave interaction by pit and be applicable to coastal engineering.

\section{THEORETICAL DEVELOPMENT}

The geometry of the problem is presented in Fig. 1. The fluid domain can be separated into three regions: the interior pit region with uniform depth $\mathrm{d}$, the refracted breakwater, and the exterior fluid region with uniform depth $\mathrm{h}$. The boundary 


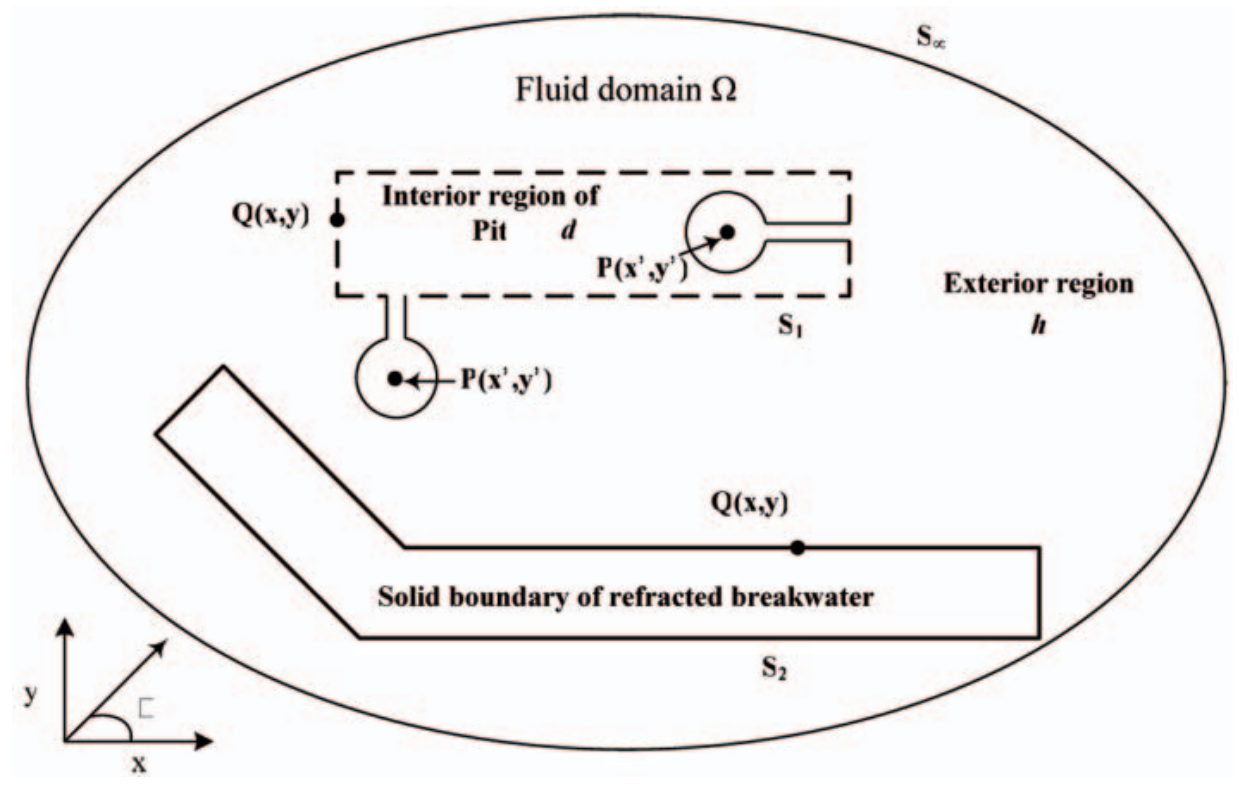

Fig. 1. Definition sketch for fluid domain and boundaries

regions express $\mathrm{S}_{1}$ (pit boundary) and $\mathrm{S}_{2}$ (breakwater region), respectively. In Fig. 1 the Cartesian coordinates are designated as having the origin at a corner of the breakwater. The $\mathrm{x}$ - and $\mathrm{y}$ - are directed in the horizontal plane and the $\mathrm{z}$-axis is directed vertically upward from at the equilibrium water surface.

The fluid region is taken to be inviscid and incompressible, and the flow irrotational, then it will be assumed that the fluid motion may be described in terms of a velocity potential $\phi_{\mathrm{j}}(\mathrm{x}, \mathrm{y}, \mathrm{z}, \mathrm{t})=\operatorname{Re}\left[\Phi_{\mathrm{j}}(\mathrm{x}, \mathrm{y}, \mathrm{z}) \mathrm{e}^{-\mathrm{i} \omega \mathrm{t}}\right]$ for $\mathrm{j}=1,2$. This potential must satisfy Laplace's equation, $\nabla^{2} \Phi_{j}=0$. It is subject to the usual boundary conditions on the free surface and seabed, and the solution of velocity potential can be given following forms:

$$
\begin{aligned}
& \Phi_{1}(\mathrm{x}, \mathrm{y}, \mathrm{z})=\Psi_{1} \cosh \left[\mathrm{k}_{1}(\mathrm{z}+\mathrm{d})\right] \text { on } \mathrm{S}_{1} \\
& \Phi_{2}(\mathrm{x}, \mathrm{y}, \mathrm{z})=\Psi_{2} \cosh \left[\mathrm{k}_{2}(\mathrm{z}+\mathrm{h})\right] \text { on } \mathrm{S}_{2}
\end{aligned}
$$

where, $\mathrm{d}$ is the water depth within the interior pit region, and $\mathrm{h}$ is the water depth of the exterior fluid region. The subscript 1 represents the pit region; subscript 2 represents the exterior fluid region, and the wave numbers $\mathrm{k}_{\mathrm{j}}(\mathrm{j}=1,2)$ are defined by:

$$
\begin{array}{lll}
\omega^{2}=g k_{1} \tanh \left(k_{1} d\right) & \text { on } & S_{1} \\
\omega^{2}=g k_{2} \tanh \left(k_{2} h\right) \text { on } S_{2}
\end{array}
$$

where:

$\omega \quad$ - angular frequency

g - gravitational acceleration.

The governing equations in each of the fluid regions should be satisfied by the Helmholtz equation.

$$
\frac{\partial^{2} \Psi}{\partial \mathrm{x}^{2}}+\frac{\partial^{2} \Psi}{\partial \mathrm{y}^{2}}+\mathrm{k}_{\mathrm{j}}^{2} \Psi=0 ; \mathrm{j}=1,2
$$

Continuity of mass flux and pressure across the fluid interface between the interior pit region $\left(\mathrm{S}_{1}\right)$ and the exterior region $\left(\mathrm{S}_{2}\right)$ requires the following conditions to be satisfied:

$$
\mathrm{d} \frac{\partial \Psi_{1}}{\partial \mathrm{n}}=\mathrm{h} \frac{\partial \Psi_{2}}{\partial \mathrm{n}} \text { on } \mathrm{S}_{1}
$$

Finally, the scattered component of the fluid potential in the $\mathrm{S}_{3}$ is subject to a radiation or far-field boundary condition at large radial distances $r$, which may be written as:

$$
\lim _{\mathrm{r} \rightarrow \infty} \sqrt{\mathrm{r}}\left(\frac{\partial}{\partial \mathrm{r}}-\mathrm{ik} \mathrm{j}\right)\left(\Psi_{3}-\Phi_{\mathrm{I}}\right)=0 ; \mathrm{j}=1,2
$$

where $\Phi_{\mathrm{I}}$ is the incident potential function and is given by:

$$
\Phi_{\mathrm{I}}(\mathrm{x}, \mathrm{y}, \mathrm{z})=-\frac{\mathrm{igH} \mathrm{I}_{\mathrm{I}}}{2 \omega} \frac{\cosh \left[\mathrm{k}_{2}(\mathrm{z}+\mathrm{h})\right]}{\cosh \left(\mathrm{k}_{2} \mathrm{~h}\right)}
$$

Green's function $G_{j}(P, Q), j=1,2$ may now be expressed for each region as:

$$
\mathrm{G}_{\mathrm{j}}(\mathrm{P}, \mathrm{Q})=\frac{\mathrm{i} \pi}{2} \mathrm{H}_{0}^{(1)}\left(\mathrm{k}_{\mathrm{j}} \mathrm{R}\right) ; \mathrm{j}=1,2
$$

where, $\mathrm{H}_{0}^{(1)}$ is the Hankel function of the first kind of order zero, $P$ and $Q$ have the coordinate of $\left(x^{\prime}, y^{\prime}\right)$ and $(x, y)$ on the boundary $\left(\mathrm{S}_{1}, \mathrm{~S}_{2}\right)$, respectively, and $\mathrm{R}=\sqrt{\left(\mathrm{x}^{\prime}-\mathrm{x}\right)^{2}+\left(\mathrm{y}^{\prime}-\mathrm{y}\right)^{2}}$.

Applying Green's second identity to $\Psi_{\text {, and }}$ extending to full regions $\left(\mathrm{S}_{1}+\mathrm{S}_{2}+\mathrm{S}_{3}\right)$, boundary integral equations can be yielded as Eq. (11) and Eq. (12).

$$
\begin{array}{r}
\Psi_{2}(P)+\frac{1}{\pi} \int_{S_{1}+S_{2}+S_{3}}\left[\Psi_{2}(Q) \cdot \frac{\partial G_{j}}{\partial n}(P, Q)-G_{j}(P, Q) \cdot \frac{\partial \Psi_{2}}{\partial n}(P)\right] d S_{j}=0 \quad ; j=1,2 \\
\Psi_{2}(P)-2 \Phi_{I}(P)-\frac{1}{\pi} \int_{S_{1}+S_{2}+S_{3}}\left[\Psi_{2}(Q) \cdot \frac{\partial G_{j}}{\partial n}(P, Q)-G_{j}(P, Q) \cdot \frac{\partial \Psi_{2}}{\partial n}(P)\right] d S_{j}=0 ; j=1,2
\end{array}
$$


The scattered wave has no effect on the imaginary boundary line $\left(\mathrm{S}_{3}\right)$, and applying boundary condition of (6) and (7) proposed by Williams (1990) and McDougal et al. (1996) to Eq. (11) and (12), and Eq. (11) and (12) become:

$$
\begin{gathered}
\Psi_{2}(\mathrm{P})+\frac{1}{\pi} \int_{\mathrm{S}_{1}}\left[\Psi_{2}(\mathrm{Q}) \cdot \frac{\partial \mathrm{G}_{1}}{\partial \mathrm{n}}(\mathrm{P}, \mathrm{Q})-\frac{\mathrm{h}}{\mathrm{d}} \mathrm{G}_{1}(\mathrm{P}, \mathrm{Q}) \cdot \frac{\partial \Psi_{2}}{\partial \mathrm{n}}(\mathrm{P})\right] \mathrm{dS}_{1}+ \\
+\frac{1}{\pi} \int_{\mathrm{S}_{2}}\left[\Psi_{2}(\mathrm{Q}) \cdot \frac{\partial \mathrm{G}_{2}}{\partial \mathrm{n}}(\mathrm{P}, \mathrm{Q})-\frac{\mathrm{h}}{\mathrm{d}} \mathrm{G}_{2}(\mathrm{P}, \mathrm{Q}) \cdot \frac{\partial \Psi_{2}}{\partial \mathrm{n}}(\mathrm{P})\right] \mathrm{dS}_{2}=0 \\
\Psi_{2}(\mathrm{P})-2 \Phi_{\mathrm{I}}(\mathrm{P})-\frac{1}{\pi} \int_{\mathrm{S}_{1}}\left[\Psi_{2}(\mathrm{Q}) \cdot \frac{\partial \mathrm{G}_{1}}{\partial \mathrm{n}}(\mathrm{P}, \mathrm{Q})-\frac{\mathrm{h}}{\mathrm{d}} \mathrm{G}_{1}(\mathrm{P}, \mathrm{Q}) \cdot \frac{\partial \Psi_{2}}{\partial \mathrm{n}}(\mathrm{P})\right] \mathrm{dS}_{1}+ \\
+\frac{1}{\pi} \int_{\mathrm{S}_{2}}\left[\Psi_{2}(\mathrm{Q}) \cdot \frac{\partial \mathrm{G}_{2}}{\partial \mathrm{n}}(\mathrm{P}, \mathrm{Q})-\frac{\mathrm{h}}{\mathrm{d}} \mathrm{G}_{2}(\mathrm{P}, \mathrm{Q}) \cdot \frac{\partial \Psi_{2}}{\partial \mathrm{n}}(\mathrm{P})\right] \mathrm{dS}_{2}=0
\end{gathered}
$$

The free surface elevation in each region can be obtained using Eq. (15):

$$
\eta_{\mathrm{j}}=-\frac{1}{\mathrm{~g}} \frac{\partial \Psi_{\mathrm{j}}}{\partial \mathrm{t}} \quad ; \mathrm{j}=1,2
$$

in which $\eta(x, y, t)=\operatorname{Re}\left\{\Delta_{j}(x, y) e^{-\omega t}\right.$, where $\Delta_{j}$ is the spatial component of surface elevation in fluid region. Finally, the diffraction coefficient of regular wave, $K_{d}$ is defined as:

$$
\mathrm{K}_{\mathrm{d}}=\left|\Psi_{\mathrm{j}}\left(\mathrm{x}^{\prime}, \mathrm{y}^{\prime}\right)\right|
$$

\section{NUMERICAL RESULTS AND ANALYSIS}

\section{Validation of the numerical model}

A computer program has been developed to implement the above theory for regular wave diffraction at the vicinity of breakwater by pit on the sea bed. To verify the present numerical results of the wave height at the front face of refracted breakwater, these were compared with the absolute and approximate solutions presented by Koji and Mutsuo (1976). The conditions of calculation and configuration of refracted breakwater in regular waves without pit by Koji and Mutsuo (1976) are defined as incident wave angle $\theta=45^{\circ}$, angle of refracted breakwater $\beta=135^{\circ}$, reflection coefficient $\mathrm{K}_{\mathrm{r}}=0.8$, and length of breakwater $=2 \mathrm{~L}\left(\mathrm{~L}_{1}+\mathrm{L}_{2}=2 \mathrm{~L}\right)$, respectively.

Fig. 2 shows a comparison of the results at the front face of refracted breakwater for the diffraction coefficient of regular waves (CD line) obtained by the present numerical model and those of Koji and Mutsuo (1976). In a comparison from fig. 2, it is noticed that reasonable agreement is shown in the three cases for the refracted breakwater, but the diffraction coefficient at the front face of refracted breakwater by the present numerical model is a little bit higher than the results of Koji and Mutsuo (1976). They had performed their studies

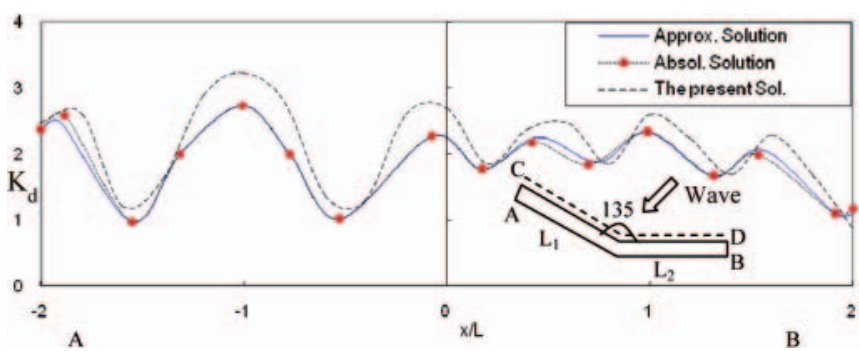

Fig. 2. Comparison of wave diffractions of present study with those of approximate and absolute solutions at the front face of refracted breakwater at the infinite refracted breakwater but the present numerical model has been investigated at the finite refracted breakwater, so in the case of finite breakwater, the wave interface has been occurred by phase difference and interaction between incident waves and reflect waves.

\section{Numerical examples}

Numerical examples are presented to investigate the influences by rectangular submarine pit at the front face of refracted and straight breakwaters with different incident wave angle.

In this study, the condition of calculations are water depth of the vicinity of breakwater $\mathrm{h}=7 \mathrm{~m}$, water depth within submarine pit region $\mathrm{h}=14 \mathrm{~m}$, the refracted angle within the refracted breakwater $\beta=160^{\circ}$, and incident wave angle $\theta=90^{\circ}$ and $\theta=135^{\circ}$ for the regular wave, respectively. Figs 3 and 4 present the results for the diffraction coefficient obtained by the present numerical model with and without submarine pit at the front face (CD line) of refracted and straight breakwater, respectively.

In the case of normal incident wave angle $\theta=90^{\circ}$, wave height reduction of refracted breakwater due to submarine pit at

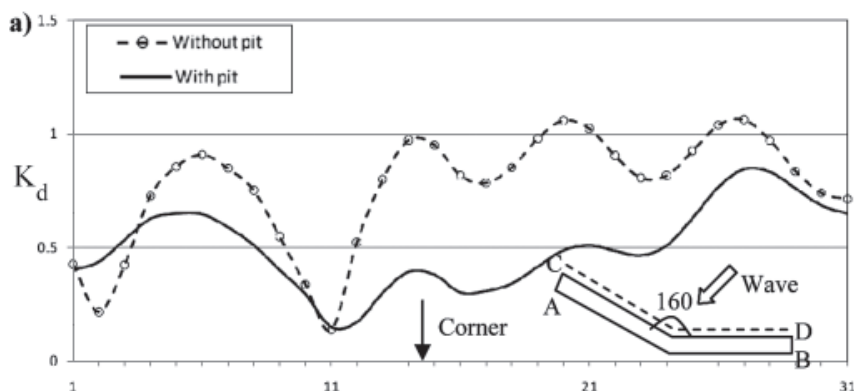

A ${ }^{3}$

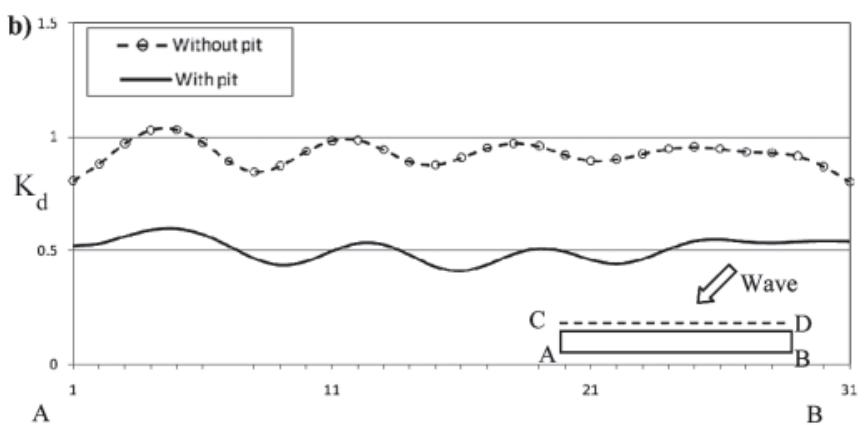

Fig. 3. Wave height distributions at the front face of breakwater systems with or without pit (incident wave angle $\theta=90^{\circ}$ ) 
the offshore sea bed as shown in fig. 3(a) can be observed at the vicinity of corner side. The wave height reduction at the vicinity of the corner side is shown to be the largest. This means that the wave energy is concentrated on the corner of the refracted breakwater, and by using the pit, the wave energy is subdued thus reducing damage on the breakwater. Fig. 3(b) shows that the straight breakwater is reduced in the entire region. This reduction is $26.5 \%$ less than the numerical results for the case without submarine pit for the refracted breakwater, and $41.7 \%$ for straight breakwater.

As for the case of inclined wave angle $\theta=135^{\circ}$, wave height reduction due to pit can be estimated $12.6 \%$ for refracted breakwater and $5.0 \%$ for straight breakwater. As shown in figs 4(a) and (b), reduced wave height is expressed at the front face of breakwater except at the left side of each breakwater. Table 1 presents the effect of added pit on the reduction in wave height line CD.

From these analyses, we find out that the overall reduction of wave height may be observed at the vicinity of breakwater with an appropriately set submarine pit.
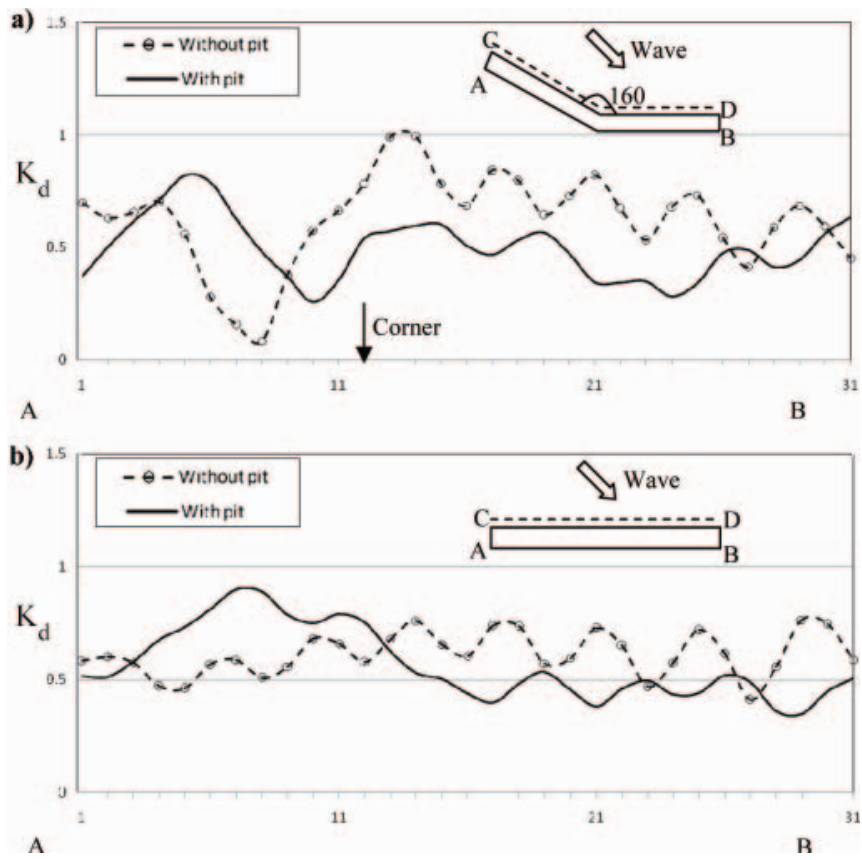

Fig. 4. Wave height distributions at the front face of breakwater systems with or without pit (incident wave angle $\theta=135^{\circ}$ )

Tab. 1. The ratio of reduction in wave height

\begin{tabular}{|c|c|c|}
\hline Type of breakwater & $\begin{array}{c}\text { Refracted } \\
\text { breakwater }\end{array}$ & $\begin{array}{c}\text { Straight } \\
\text { breakwater }\end{array}$ \\
\hline$\theta=90^{\circ}$ & $26.5 \%$ & $41.7 \%$ \\
\hline$\theta=135^{\circ}$ & $12.6 \%$ & $5.0 \%$ \\
\hline
\end{tabular}

Fig. 5 presents the contours of the wave height ratios near the breakwaters due to regular diffraction wave with two case of breakwater. We can derive from the results that a dredging pit may provide an excellent means of protection from a wave attack. It can be seen that wave energy is weakened by discontinuity water depth (dredging). The results from numerical simulation for wave diffraction indicate that the present model is appreciable to estimate the wave field at the vicinity of breakwater when a pit is dredged on the offshore sea bed.
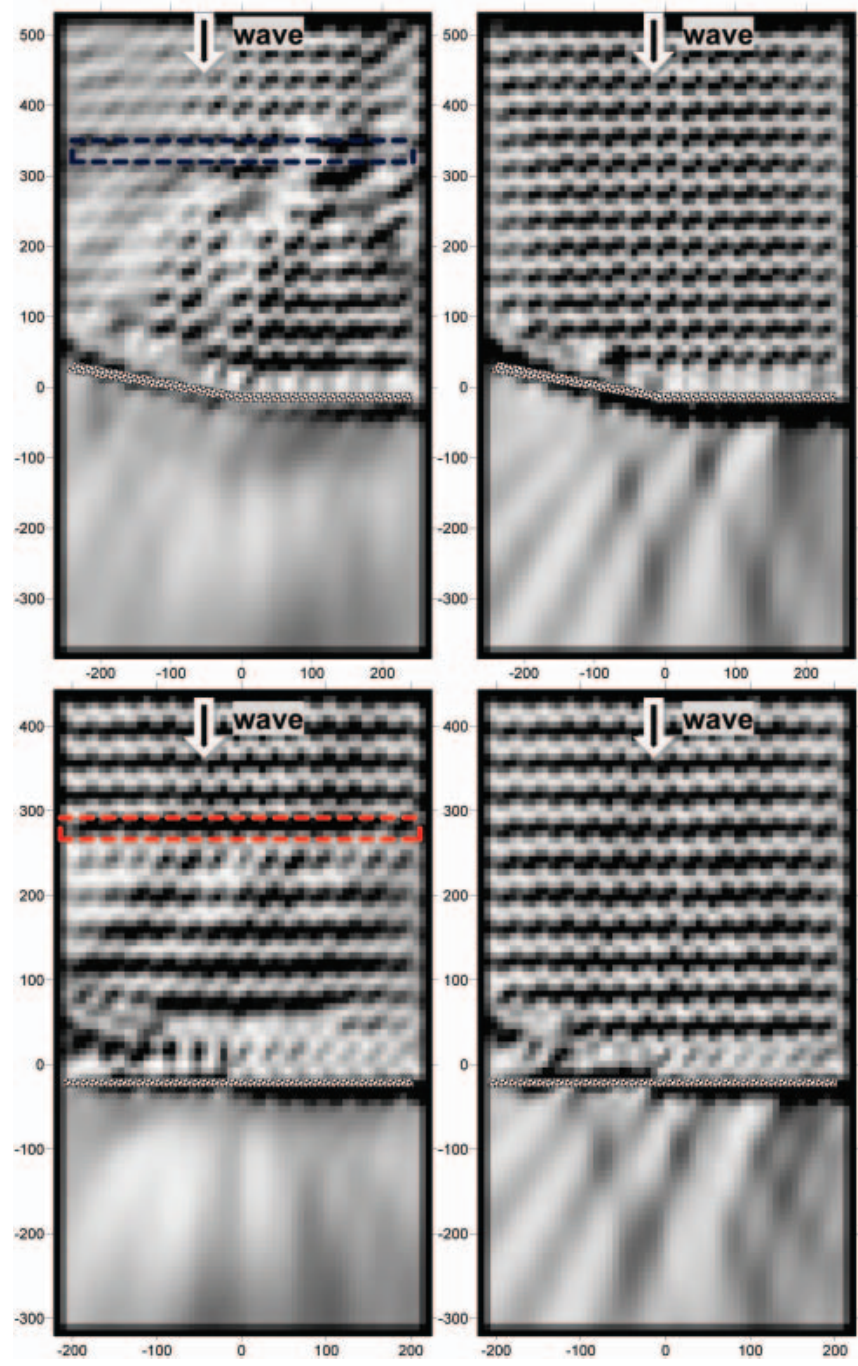

Fig. 5. Diffraction contour plots at the vicinity of breakwaters with or without pit

\section{CONCLUSIONS}

The purpose of this study was to estimate the decreasing effects of diffracted wave fields around breakwater when the dredging work (pit) is performed at the offshore sea bed. This study is about the composite interaction for the three problems: dredging boundaries, depth discontinuity of pit, and breakwater boundaries. The boundary conditions are established for those problems and applied to the boundary integral equation.

Results for the incident wave conditions have been presented to illustrate the wave height distribution of the wave field near breakwater by the influence of the pit. The results of present numerical model have been compared with those from published calculations and present numerical simulations that show relative agreement with published data for diffraction.

- Through the present numerical simulations the wave height reduction of refracted and straight breakwater with different incident wave angle due to submarine pit at the offshore sea bed can be observed.

It is noticed that the results from the present numerical model accurately provides the diffracted wave height of vicinity of breakwater systems, when the pit is dredged on the offshore sea bed, and so may be extended to apply with confidence in breakwater planning and design applications. 


\section{BIBLIOGRAPHY}

1. HILAY N.: Water waves over a rectangular channel though a reef. Journal of Waterways and Harbor Division, ASCE, 95(1):77-94, 1969.

2. Kim S.D.: Multidirectional random wave diffraction in a harbor with partial-reflecting boundary by placing submarine pit. Ph.D. Thesis, Chung-Ang University, South Korea, 2007.

3. KIRBY J.T. and DALRYMPLE R.A.: Propagation of obliquely incident water waves over a Trench. Journal of Fluid Mechanics, 133: 47-63, 1983.

4. KIRBY J.T., DALRYMPLE R.A. and SEO S.N.: Propagation of obliquely incident water waves over a trench. Part 2. Current flowing along the trench, Journal of Fluid Mechanics, 176: 95116, 1987.

5. KOJI K. and MUTSUO O.: A study of wave height distribution along a breakwater with a corner. Report of the Port \& Harbor Research Institute, 15(2): 55-88, 1976.

6. LEE J.J. and AYER R.M.: Wave propagation over a rectangular trench. Journal of Fluid Mechanics, 110: 335-347, 1981.

7. MCDOUGAL W.G., WILLIAMS A.N. and FURUKAWA K.: Multiple-pit breakwaters, Journal of Waterway. Port, Coastal and Ocean Engineering, ASCE, 122(1): 27-33, 1996.

8. MILES J.W.: On surface wave diffraction by a trench. Journal of Fluid Mechanics, 115: 315-25, 1982.

9. NEWMAN J.N.: Propagation of water waves over an infinite step. Journal of Fluid Mechanics, 23: 399-415, 1965.
10.TING C.K.F. and RAICHLEN F.: Wave interaction with a rectangular trench. Journal of Waterway. Port, Coastal and Ocean Engineering, ASCE, 112, 454-460, 1986.

11. WILLIAMS A.N.: Diffraction of long waves by rectangular pit. Journal of Waterway, Port, Coastal and Ocean Engineering, ASCE, 116(4): 459-469, 1990.

12. WILLIAMS A.N. and VAZQUEZ J.H.: Wave interaction with a rectangular pit. Journal of Offshore Mechanics and Arctic Engineering, 113: 193-198, 1991.

\section{CONTACT WITH THE AUTHORS}

Sung Duk Kim, Ph.D.

Department of Civil \& Environmental Engineering, Chung-Ang University, South Korea.

Donjak Gu, Heukseok-Dong 221, Seoul, South Korea Phone: +82-2-820-5253, fax: +82-2-820-5253, e-mail: soungdoug@hotmail.com

Ho Jin Lee (Corresponding author), Ph.D.

Department of Civil \& Environmental Engineering, Colorado State University, USA. Fort Collins, CO 80523, USA e-mail: leehojin74@gmail.com 